
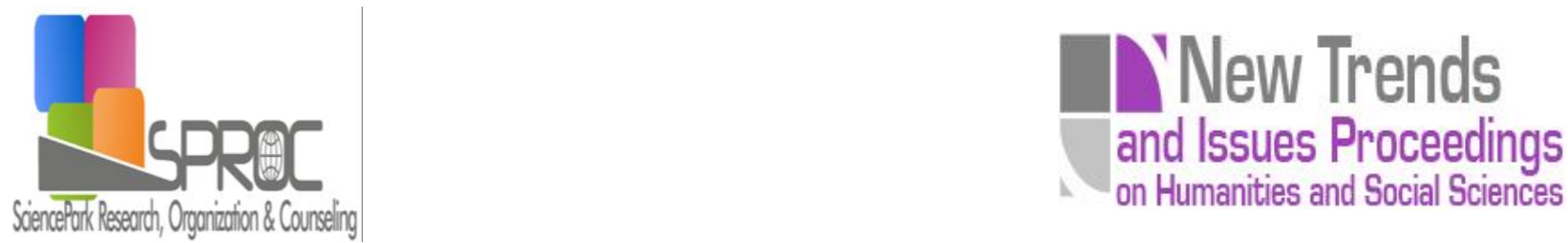

\title{
Effects of mental training practice in Alpine skiers through imagery and NLP techniques
}

Grosu Vlad Teodor ${ }^{\text {* }}$

Grosu Emilia Florinab

Moisa Adria, Babes ${ }^{c}$

Cristina Elena Moraru ${ }^{d}$

Suggested Citation:

I I

Sciences.

New Trends and Issues Proceedings on Humanities and Social

Abstract 
1. Introduction

I I 
I

New Trends and Issues Proceedings on Humanities and Social Sciences.

2. Material and method

I

2.1 Findings and Discussions

Table 1. Descriptive statistics 


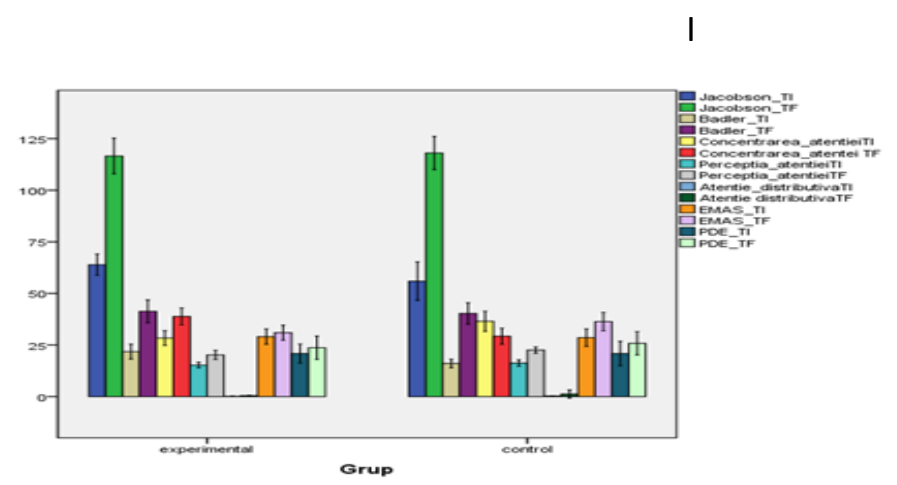

Figure 1. Comparison of means in the psychological tests Le and LC

$\boldsymbol{t}$

I

Table 2. $T$ test for independent samples

$\boldsymbol{t}$ 
I

3. Conclusions and recommendations

self-confidence focusing on being a winner

lower anxiety and emotional distress.

increases concentration, 


\section{References}

।

I

I
NLP per il Benessere

Sport psychology for coaches, human kinetics $M$

Sport slump busting: 10 steps to mental toughness and peak performance

$\mathrm{M}$

Int J Sports Med. , 11

Journal of Applied Sport Psychology, 20

Enzyklopädie der Psychologie I

NLP per il problem solving

Journal of Applied Sport Psychology 14

I

. Journal The Sport Psychologist 21,

Basic principles mental toughness training

Athletic excellence: Mental toughness training for sport

Mental toughness training for sport: Achieving athletic excellence

I

I

Annual Review of Neuroscience, 27

The mental skills training of

university soccer players International Education Studies 3

Pediatric Annals 39

Hirnforschung für Neu ro gierige

I Foundations of sport and exercise psychology

M 